\title{
O CORPO (INTER)FACE: SENTIDOS SOBRE A RELAÇÁO SUJEITO, CORPO E OBJETOS TECNOLÓGICOS DE CONEXÃO À REDE ELETRÔNICA ${ }^{1}$
}

\author{
Daiana de Oliveira Faria \\ Universidade de São Paulo, USP, Ribeirão Preto, SP, Brasil \\ Laboratório E-L@DIS
}

A tese intitulada $O$ corpo (inter)face: sentidos sobre a relaçáo sujeito, corpo e objetos tecnológicos de conexão à rede eletrônica, de Daniela Giorgenon, sob orientação da Profa. Dr. Lucília Maria Abrahão e Sousa, trata da relação entre sujeito, corpo e objetos tecnológicos de conexáo à rede eletrônica. Tal relação é traçada sob a ótica da Análise do Discurso de linha francesa, buscando subsídios também na Psicanálise (PÊCHEUX, 2009; FREUD, 1930; LACAN, 1995). Com esse embasamento teórico, Giorgenon fundamenta pressupostos acerca de um corpo fusionado, silenciado e ilimitado na relação com os referidos objetos. Pontua a necessidade de complementaridade do corpo com o objeto, naturalizada na conjuntura contemporânea com a nomeação "ciborgue", que define a relação organismomáquina (HARAWAY, 2009). Para sustentar sua tese, a autora propóe a noção corpo (inter)face que corrobora a filiação à formação discursiva (FD) do mercado em que o corpo é interface do objeto tecnológico; FD recorrente nos discursos produzidos e analisados no período de agosto de 2012 a agosto de 2014. Pelo caminho percorrido, Giorgenon tece conclusóes sobre a potência de um corpo instaurada pelo acoplamento à máquina que, por sua vez, a esse corpo promove inércia, na medida em que a intensa experiência na esfera virtual demanda ao corpo apenas um "piscar de olhos" que aciona o dispositivo tecnológico a ele acoplado.

\footnotetext{
${ }^{1}$ Resumo da tese de doutoramento homônima de Daniela Giorgenon, defendida em maio de 2016, sob orientação da Profa . Dr. L. D. Lucília Maria Abrahão e Sousa, junto ao Programa de Pós-Graduação em Psicologia da Faculdade de Filosofia, Ciências e Letras de Ribeirão Preto, Universidade de São Paulo (PPGP/FFCLRP/USP).
} 